\title{
Renal AA amyloidosis in a patient with Bence Jones proteinuria and ankylosing spondylitis
}

\author{
R Quinton, P D Siersema, J J Michiels, F J W ten Kate
}

\begin{abstract}
A patient with a 10 year history of monoclonal gammopathy of undetermined significance and Bence Jones proteinuria, and a 44 year history of ankylosing spondylitis, developed a nephrotic syndrome secondary to renal amyloidosis. Clinically the amyloidosis was ascribed to Bence Jones proteinuria rather than to the burnt out ankylosing spondylitis. However, histochemical and immunofluorescence staining techniques used to type the amyloid fibrils showed AA amyloidosis, implicating ankylosing spondylitis rather than monoclonal gammopathy as the underlying cause of the patient's systemic amyloidosis and consequent nephrotic syndrome.

It is recommended that immunostaining of amyloid become a routine procedure to detect occult or apparently inactive disease.
\end{abstract}

(F Clin Pathol 1992;45:934-936)

The amyloidoses can be subdivided into three groups: primary amyloidosis of uncertain aetiology (comprising rare heredofamilial forms such as familial Mediterranean fever, together with senile and localised amyloidosis); amyloid secondary to immunocyte dyscrasias; and reactive systemic amyloidosis. Amyloid deposition in the latter is related to chronic inflammation, as occurs in collagen vascular diseases, chronic infections and certain neoplasms. The structure of the amyloid fibrils deposited in reactive systemic amyloidosis is related to that of an acute phase reactant, serum amyloid A protein (SAA), from which the fibrils are most probably derived; hence the term amyloid A derived, or AA fibrils. The development of AA amyloidosis in certain people is probably the result of defective catabolism of SAA. ${ }^{1}$ The amyloid fibrils associated with monoclonal gammopathy are virtually identical with immunoglobulin light chains; hence amyloid light chain derived, or AL fibrils.

These two types of amyloid fibril are indistinguishable by standard Congo red or metachromic stains. They must be differentiated either by immunostaining with appropriate antisera to amyloid fibril components (probably the most straightforward method), or by Wright's technique, in which pretreating the slide with potassium permanganate solution prevents uptake of Congo red stain by AA but not by AL amyloid fibrils. ${ }^{2}$

\section{Case report}

A 64 year old native Dutchman had had low backache since 1946, when it had excused him from military service. In 1973 he was diagnosed as having ankylosing spondylitis on the basis of clinical and radiological findings, but in recent years the disease had largely burnt out.

In 1980 serum protein electrophoresis, performed because of a raised erthrocyte sedimentation rate, showed a minor spike of IgG monoclonal paraprotein. A bone marrow aspirate showed normocellular marrow with a highnormal proportion of plasma cells $(4 \%)$. In 1983 plasmacytosis of $10 \cdot 2 \%$ with a proportion of atypical plasma cells was seen in the bone marrow and Bence Jones $\lambda$ light chains were detected in an early morning urine sample.

The patient was referred in 1990 , complaining of general malaise and a swollen face and ankles. On admission he had bilateral pitting oedema of his ankles, together with a rigid lumbar spine and limited chest expansion. He was otherwise fit for his age. In particular there was no macroglossia, purpura, or hepatosplenomegaly, nor clinically impaired autonomic or cardiac function.

\section{Methods}

The most relevant histochemical staining procedure was the Congo red stain, with and without pretreatment with potassium permanganate solution. ${ }^{2}$ For the immunofluorescence study antibodies against amyloid A component (monoclonal mouse antihuman fluorescein conjugate; Dako A/S, Denmark), and against $\kappa$ and $\lambda$ light chains (monoclonal mouse antihuman fluorescein conjugates; Nordic Immunological Laboratories, The Netherlands) were used according to manufacturers' instructions.

\section{Results}

The patient's haemoglobin was $11.8 \mathrm{~g} / \mathrm{dl}$, urea $12.6 \mathrm{mmol} / \mathrm{l}$, creatinine $0.185 \mathrm{mmol} / 1$, calcium $2.00 \mathrm{mmol} / 1$, albumin $24 \mathrm{~g} / 1, \mathrm{ESR} 94 \mathrm{~mm}$ in the first hour, C-reactive protein $59 \mathrm{mg} /$, $\beta$-2-microglobulin $6.9 \mathrm{mg} / \mathrm{l}$, and IgG $22.6 \mathrm{~g} / \mathrm{l}$, IgA $1.89 \mathrm{~g} / 1$, IgM $0.59 \mathrm{~g} / \mathrm{l}$. The creatinine clearance was $31 \mathrm{ml} / \mathrm{minute}$. Urinary protein excretion was $6.6 \mathrm{~g} / 24$ hours. Urinary Bence 
Jones excretion consisting of monoclonal $\lambda$ light chains was $2.4 \mathrm{~g} / 24$ hours.

Bone marrow morphology and immunocytology showed that the marrow was normocellular with $7 \cdot 2 \% \operatorname{IgG}_{2}-\lambda$ monoclonal plasma cells. The electrocardiogram was normal with no conduction defects. An abdominal ultrasound scan showed normal sized kidneys of enhanced echogenicity. A skeletal survey showed no osteolysis or osteoporosis, though bilaterally fused sacroiliac joints and a classic "bamboo" appearance of the lumbar spine were evident (fig 1).

Congo red staining of a renal biopsy specimen showed heavy deposition of amyloid protein in the mesangium and atrophic tubuli (not illustrated). Unfortunately, there remained insufficient unstained kidney tissue to differentiate safely between $\mathrm{AA}$ and $\mathrm{AL}$ fibrils. Given the patient's impaired renal function it was thought inappropriate to perform another kidney biopsy and a rectal specimen was obtained. In this specimen heavy amyloid deposition in submucosal vessel walls was shown by Congo red staining. Histochemical staining of the rectal biopsy specimen, according to Wright's technique, was characteristic of AA fibrils. ${ }^{2}$ Immunostaining for AA

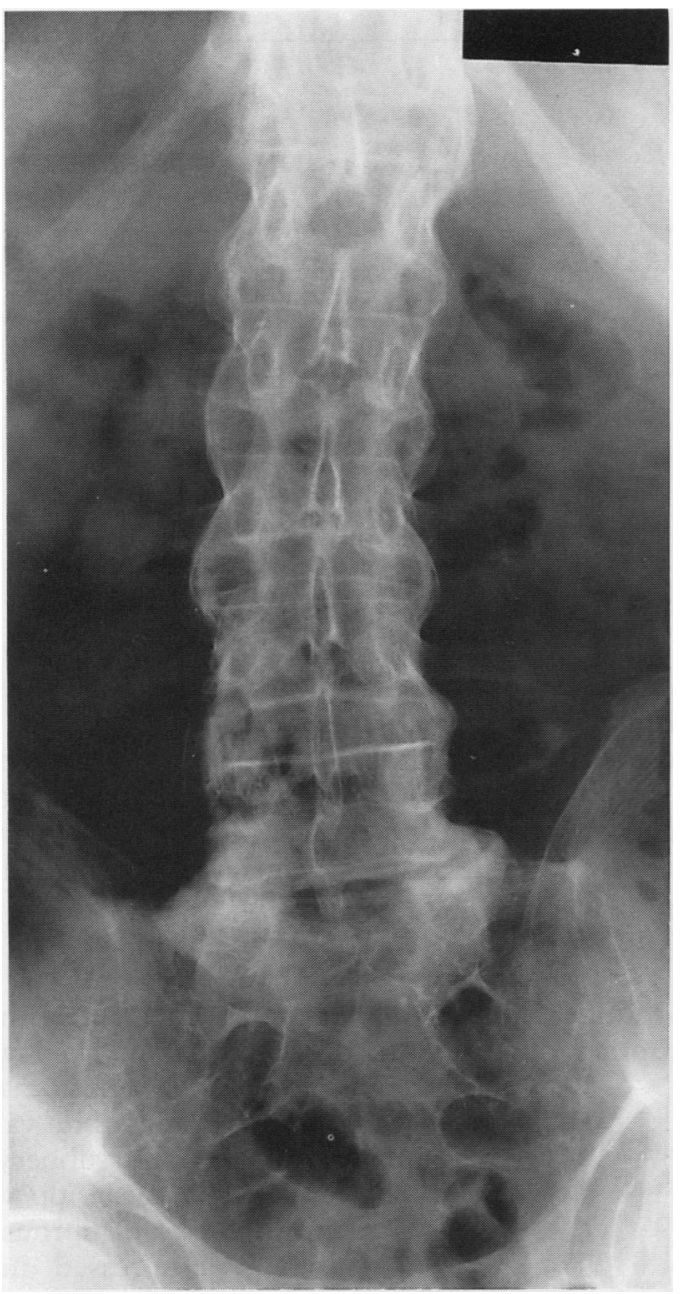

Figure 1 Posterior-anterior radiograph of lumbar spine showing classic "bamboo" appearance and fused sacroiliac joints, characteristic of ankylosing spondylitis. fibrils in the rectal biopsy specimen was strongly positive (fig 2 ) and gave an identical picture with that obtained with Congo red stain. Immunofluorescence staining for $\lambda$ and, to a lesser extent, $\kappa$ immunoglobulin light chains was slightly positive (not illustrated).

\section{Discussion}

The renal amyloidosis and consequent nephrotic syndrome was initially ascribed to progression of the monoclonal gammopathy and Bence Jones proteinuria, rather than to the inactive ankylosing spondylitis. However, no clinically relevant disease progression could be seen on comparing current bone marrow morphology with that seen eight years earlier; nor was there any radiological evidence for myelomatosis. The histochemical staining characteristics of the amyloid protein seen in the rectal tissue were not those of AL fibrils, as expected, but of AA fibrils. ${ }^{2}$ This concurred with the positive anti-AA immunostaining. ${ }^{3}$

It was impossible to exclude completely a contribution from light chain deposition to the patient's renal amyloid, but the patient certainly had a predominantly AA amyloidosis. As there was no evidence for any other chronic inflammatory disease or malignancy, the patient's AA amyloidosis was attributed to ankylosing spondylitis. Amyloidosis is a rare but known consequence of ankylosing spondylitis. The association was first mentioned by Bayles in $1943 .^{4}$ Depending on the sample population, amyloidosis has been found to occur in $1 \cdot 5-18 \%$ of patients with ankylosing

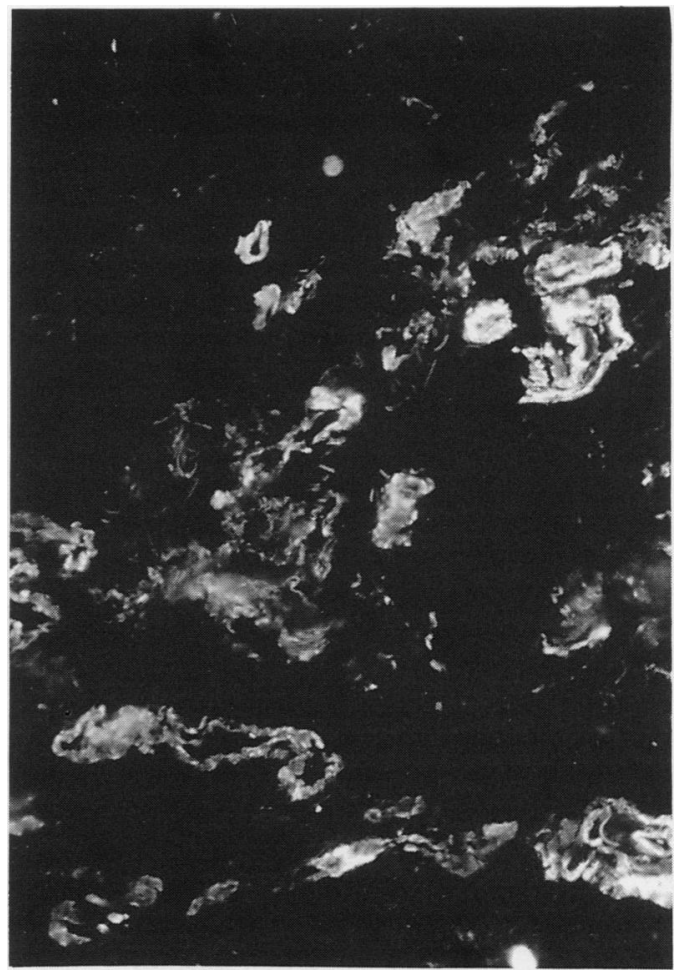

Figure 2 Rectal biopsy specimen tested with fluorescence antibody to $A A$ amyloid showing extensive staining for amyloid $A$ component in walls of small vessels in the submucosa. 
spondylitis. ${ }^{5}$ Hajjaj-Hassiouni et al described two cases of ankylosing spondylitis with the nephrotic syndrome where amyloid was demonstrated in a rectal biopsy specimen, ${ }^{6}$ Geffriaud et al followed up six patients with systemic AA amyloidosis and ankylosing spondylitis. ${ }^{5}$ Renal failure eventually occurred in all six between three and 31 years (with a mean of 19 years) after the onset of rheumatological symptoms.

Amyloidosis is a well recognised cause of the nephrotic syndrome, and end stage renal failure is the cause of death in $13-68 \%$ of cases of systemic AA amyloidosis. ${ }^{157-10}$ AA amyloidosis may present many years after the onset of the underlying inflammatory disorder, which may appear to be clinically inactive at the time of presentation. ${ }^{9}$ In a recently published series from the Mayo Clinic the mean time elapsed between onset of symptoms attributable to inflammatory disease and a tissue diagnosis of AA amyloid was 18.3 years. ${ }^{1}$

Our patient developed a nephrotic syndrome 44 years after the onset of symptoms attributable to ankylosing spondylitis. At the time of writing he retains adequate renal function. Progression of his renal disease has thus been slower than in the six patients in Geffriaud's series. ${ }^{5}$

Immunostaining of amyloid with specific antisera to the components of amyloid fibrils is not routinely performed in many pathology departments including, until now, our own. In the authors' opinion this case shows that immunostaining of amyloid should be routinely adopted to avoid overlooking occult or apparently quiescent underlying disease.

We thank Professor Robert A Kyle for reading the manuscript and giving us the benefit of his long experience in the field of amyloidosis.

1 Gertz MA, Kyle RA. Secondary systemic amyloidosis: response and survival in 64 patients. Medicine 1991;70: 246-2.

2 Wright JR, Calkins E, Humphrey RL. Potassium permanganate reaction in amyloidosis. Lab Invest 1977;36: 274-81.

3 Noël LH, Droz D, Ganeval D. Immunohistochemical characterisation of renal amyloidosis. Am $\mathcal{f}$ Clin Pathol 1987;87:756-61.

4 Bayles TB. Rheumatoid arthritis and rheumatic heart disease in autopsied cases. Am $\mathcal{F}$ Med Sci 1943;205: 42-8.

5 Geffriaud C, Noël LH, Blanche P, et al. Spondylarthritis ankylosante avec amylose de type AA: six observations.

Press Med 1988;17:2344-7.
6 Hajjaj-Hassiouni N, Laghrissi S, Khalil A, et al. Spondylarthrite ankylosante et amylose: deux observations. Rev Rheum 1988;49:687-91.

7 Brandt K, Cathcart E, Cohen AS. A clinical analysis of the course and prognosis of forty-two patients with amyloidosis. Am ₹ Med 1968;44:955-9.

8 Kyle RA, Bayrd ED. Amyloidosis: a review of 236 cases. Medicine 1975;54:271-99.

9 Wright JR, Calkins E. Clinical pathological differentiation of common amyloid syndromes. Medicine 1981;60: 429-48.

10 Triger DR, Jokes AM. Renal amyloidosis. A 14 year followup. $Q f$ Med 1973;165:15-40.

\title{
Lobular carcinoma in a mammary hamartoma
}

\author{
J Coyne, F M Hobbs, C Boggis, R Harland
}

\footnotetext{
Department of Histopathology

J Coyne

F M Hobbs

Department of

Radiology

C Boggis

Department of

Surgery

R Harland

Withington Hospital, Manchester

Correspondence to:

Dr J Coyne,

Department of

Histopathology, Withington

Hospital, Nell Lane,

Manchester M20 8LR.

24 March 1992
}

\begin{abstract}
Mammary hamartomas are uncommon breast lesions, sometimes presenting as mammographic abnormalities which require pathological clarification. Previous cases have all been benign. A unique case of mammary hamartoma containing atypical lobular hyperplasia (ALH), lobular carcinoma in situ (LCIS), and foci of microinvasive lobular carcinoma is presented. The need for adequately sampling macroscopically innocuous breast lesions is emphasised.
\end{abstract}

(F Clin Pathol 1992;45:936-937)

\section{Case report}

A 59 year old woman had a $5 \mathrm{~cm}$, well defined opacity incorporating a fatty component, which was located in the upper, inner quadrant of the left breast, detected at mammography (fig 1). A soft, round, mobile mass was palpable and this was considered to be benign clinically. A fine needle aspirate showed very few, small clusters of benign epithelial cells. Because of the patient's anxiety, an excision biopsy was performed.

\section{Pathology}

The specimen measured $6 \times 5 \times 3 \mathrm{~cm}$ and contained an ovoid well circumscribed mass measuring $3 \mathrm{~cm}$ in maximum diameter. It had a yellow and white variegated cut surface and was firm and rubbery in consistency. Microscopically, the lesion was focally surrounded by a thin layer of fibrous tissue containing occasional compressed ducts. The overall pattern consisted of individual and clustered lobular units separated by dense, hyalinised fibrous tissue which were separated by abundant fatty 